\title{
Digital Transformation, Robotics, Artificial Intelligence, and Innovation
}

\author{
Oluremi B. Ayoko \\ University of Queensland, Brisbane, Australia (Editor in Chief, JMO) \\ r.ayoko@business.uq.edu.au
}

Contemporary business organizations continue to embrace Digital Transformation (DT) on the back of the accelerated progress in technology, algorithms, internet, interconnectedness, and big data storage (Foerster-Metz, Marquardt, Golowko, Kompalla, \& Hell, 2018; Hanelta, Bohnsack, Marzc and Maranteb, 2021). The pervasive adoption of digital technologies has generated extensive transformation in organizations, which is expected to impact organizations' internal operations and processes (Kretschmer \& Khashabi, 2020; Magistretti, Pham, \& Dell'Era, 2021). Especially, organizations perceive that digitalization will assist them to radically improve their efficiency and effectiveness in the way they organize resources, staffing, culture, decision making (Devonport, 2018), and internal education tailored training (Foerster-Metz et al., 2018) for competitive advantage.

Given that DT is multidimensional (Appio, Frattini, Petruzzelli and Neirotti, 2021; Zangiacomi, Pessot, Fornasiero, Bertetti, \& Sacco, 2020), researchers define it variously (see Verhoef, Broekhuizen, Bart, Bhattacharya, Dong, Fabian, \& Haenlein, 2021; Vial, 2019). Indeed, Warner and Wager (2019) suggest that DT suffers from a lack of common agreement on exactly what it is and what it entails (Wessel, Baiyere, Ologeanu-Taddei, Cha, \& Blegind-Jensen, 2021). However, it is agreed that DT can be described as an emerging integration of new digital technologies into the fabric of an organisation suggesting a need to transform the traditional business models (Reier Forradellas, \& Garay Gallastegui, 2021). Especially, Tang (2021) argues that DT is driven by trends in technology such as social media, mobility, internet of things (IoT), cyber security, big data and analytics, cloud computing, robotics, automation, artificial intelligence (AI, including Machine Learning). These technological trends provide businesses with the capability to fully digitize, transform, and grow their organizations spanning both growth and operational improvement, and are associated with organizational strategic renewal (Kretschmar \& Khashabi, 2020).

Against this backdrop, the collections of papers in this current issue (27.5) examine the intersection between DT, the Robotics, AI, and Innovation. The first paper is from an emerging economy and tackles the issue of DT head on. In this paper, "Digital transformation: a conceptual framing for attaining sustainable development goals 4 and 9 in Nigeria", the authors Ufua, Emielu, Olujobi, Lakhani, Borishade, Ibidunni and Osabuohien explore the potentials of digital transformation for achieving the United Nations Sustainable Development Goals (SDGs), with emphasis on SDG 4 and SDG 9 in Nigeria. The study adopts a conceptual approach and focuses on the contextual factors such as stakeholder input to the process of implementing digitalisation and SDGs 4 and 9. These goals primarily target development of education at all levels, industrial collaboration, and improvements. Literature review indicates that digital transformation potentially enhances the attainment of SDGs 4 and 9, but this is mediated by the level of stakeholder commitment and e-governance performance. The authors recommend the adoption of a multidisciplinary approach to development-oriented digital transformation interventions for SDGs 4 and 9 in Nigeria, through a process of effective stakeholder engagement and transparent 
institutional signalling. Attention is also drawn to the use of digital transformation for social development, (e.g., in developing economies), to enhance the compendium of knowledge in the implementation of digital approach to the attainment of SDGs 4 and 9. Governments are encouraged to provide a fair platform for the implementation of digital transformation and the attainment of SDGs 4 and 9.

Melián-González and Bulchand-Gidumal dig deeper into the issue of DT by examining digital platforms and the digital labor market in their paper, "What type of labor lies behind the on-demand economy?" They look at popular digital platforms such as Uber, TaskRabbit, and Upwork and argue that the term digital labor market distinguishes the work mediated by these platforms from that of the traditional labor market. They further theorise that the work conditions and characteristics of this digital labor market are like those of negative nonstandard work arrangements. Based on data from 465 workers (extracted from two digital platforms), characteristics commonly attributed to the digital labor market are identified. Their results confirm and refine some of the beliefs found in the literature.

The next three papers are on robotics and AI. Robotics is the interdisciplinary subdivision of engineering and science involving the design, construction, operation and use of robotics (Rouse, $2017 \mathrm{~b}$ ). The field of robotics deals with programmable machines (e.g., using AI) that interact with the physical environment through sensors and actuators. Robots are usually able to carry out a series of activities both in semi-autonomous and autonomous modes. This suggests that some automation is involved, and this automation has to do with the procedure of making a machine, a process, or a system to be automatically run with no or reduced human involvement. In this respect, some robotics are fully automated with processing of structured business processes (repeatable and predictable interactions) by software robots or by using artificial intelligence (AI). Associated with robotics is intelligent automation which is an emerging and expensive technology that enables automating non-routine tasks like intuition, judgement, creativity, problem solving, and are predicated on dynamic information (Deloitte, 2017). Notably, robotics is already assisting technology in rehabilitation, surgery, therapy, and entertainment (Winkle et al., 2019).

AI takes a step further than robotics and machine learning (Ayoko \&Ashkanasy, 2020). Ayoko and Ashkanasy argue that this is because AI technology is removed from the need for physical embodiment and has the capability to interact with humans in their routine work to optimise solutions faster with increased accuracy. Sometimes considered a disruptive technological development from the 20th Century (Ruiz-Real, Uribe-Toril, Torres \& De Pablo, (2021), the term AI was first coined by McCarthy to describe the science and engineering of making intelligent machines (McCarthy, 1958). Today, AI describes the use of digital computers or computercontrolled robots to perform activities commonly associated with intelligent human beings such as language, learning, perception, reasoning, problem-solving and even playing games (Balajee, 2020; see also McKinsey, 2017; Ulrike, Foerster-Metz, Marquardt, Golowko, Kompalla and Hell, 2018). In this regard, AI strives to convert non-analytical human knowledge into computational data from a combination of symbolic computational processes, and connectionist network to increase competitive advantage (Ruiz-Real, Uribe-Toril, Torres, and De Pablo, 2021). Both AI and Robotics do overlap and work hand in hand. In this respect, AI-equipped robots are partly autonomous and carry out their missions in the immediate environment and frequently interact with humans such as robots e.g., fetching desired food (Severisnson-Eklundh, 2003).

While the development of AI and robotics have created new opportunities and challenges in industries (Xu \& Wang, 2019), the tension between robots and humans has stimulated extensive interest among researchers in law. In an exploratory study, the paper, "Adopting robot lawyer? The extending artificial intelligence robot lawyer technology acceptance model for legal industry by an exploratory study", Xu and Wang investigate the introduction of robots to the practice of legal service through semi structured interviews with lawyers, judges, artificial intelligence experts, and potential clients. An extended robot lawyer technology acceptance model is proposed. The model highlights two dimensions: 'legal use' and 'perception of trust.' The study 
asserts that while artificial intelligence robot lawyers are being developed with some of the abilities necessary to substitute human beings, working with human lawyers is imperative to produce benefits from this type of reciprocity.

Continuing the theme of AI and Robotics, our next paper, "From dreams to reality: a phenomenological study of the psychological contracts of ex-military personnel in the Australian Defence Force", Naweed, Hodgkinson and Matthews acknowledge that the Australian Defence Force (ADF) is currently going through technological changes with a new generation of ships, submarines, planes, and land vehicles, as well as advancements in communications, cyber, and artificial intelligence technologies. Their paper combined a phenomenological approach with the critical decision method to investigate the lived experiences informing contract formation and contract trajectory of ex-military personnel. The lived experiences pointed to the formulation of 'fuzzy' contracts, impressions from defence force recruitment, specific tipping points around organisational commitment, and large differences between the fidelity of the idealised and actualised self/job. Seven superordinate themes tracing the formation and trajectory of the contract were elicited. A schematised account of findings was developed to provide avenues to investigate how beliefs form in a military contract context and their outcomes.

The last paper in the theme of DT, AI and robotics is by Whitty. In the paper, "Developing a conceptual model for insider threat", Whitty analyses 99 case studies of insider attacks that took place in the UK. The analysis elucidates how to identify insiders and pathways to these attacks. The paper also highlights examples of archetypal insiders such as the 'disgruntled employee', 'the show-off, 'the career criminal' and 'the addict' while highlighting multiple pathways to an attack. Then, the paper presents a conceptual model of how indicators (both physical and cyber) might be monitored in an insider risk detection programme. The model stressors need to continuously seek out methods to close opportunities as well as monitor behavioural change. Finally, it elucidates potential deterrence and prevention strategies for organisations to consider in an ethical and legal manner.

The last three papers in our current issue speak to innovation. The paper, "Leaders who empower: a gateway to radical innovation” by Domínguez-Escrig, Mallén Broch, Alcamí, and Gómez analyze the relationship between leaders' empowerment, radical innovation and organizational performance. Data from 300 Spanish companies validated all the hypothesised relationships in the theoretical model. Especially, the study provides empirical evidence of the relationship between leaders' empowerment and organizational performance, highlighting the mediation role played by radical innovation. Altogether, leaders who empower also promote radical innovation and, in turn, performance.

In the next paper, "Knowledge flows, strategic motives and innovation performance: Insights from Australian and New Zealand investment in Europe", Ingršt, and Zámborský investigate the international innovation strategies of Australian and New Zealand (ANZ) firms in the European context, to explain their investment motives, knowledge flows, and innovation performance. The thematic analysis of seven case studies suggests that, on the one hand, the ANZ investors' motives for innovation in Europe are often both market and knowledge-seeking and that some are also motivated by diversification and cooperation. Additionally, the strategic intent is often for the knowledge to flow in multiple directions among subsidiaries and headquarters (HQ). Distance poses challenges to the efficiency of the process. The European subsidiaries on the other hand, are often seen as potentially playing a key role in firms' global innovation systems, particularly with regards to radical innovation. However, because of distance and communication bottlenecks (e.g., time zone differences), HQ does not always recognise this potential. The paper develops a model proposing that HQ-subsidiary trust and strategic motives are moderators in the process of international knowledge connectivity and knowledge creation.

Our last paper in the issue, "Organizational innovation culture and firms' new product performance in two emerging markets: The moderating effects of institutional environments and organizational cohesion by $\mathrm{Xie}, \mathrm{Wu}, \mathrm{Xie}, \mathrm{Yu}$ and Wang addresses innovation cultures in the 
context of emerging markets. The analysis of data from 433 Chinese and Vietnamese manufacturing firms shows that there are positive relationships between organizational innovation culture and firms' new product performance. Additionally, organizational cohesion is shown to have both a direct, positive effect on new product performance and a positive moderating role in the relationship between organizational innovation culture and firms' new product performance. The results also show that the effects of organizational innovation culture on firms' new product performance are stronger in China than in Vietnam. The paper enriches organizational culture research by providing a multidimensional theoretical framework while extending institutional theory in the context of emerging markets.

\section{Conclusion}

DT, Robotics and AI are ultimately connected with organisational outcomes such as innovation and organizational behaviors. There are suggestions that about $54 \%$ of employers acknowledge that achieving the right human machine collaboration model is critical in realising their goals, and that $63 \%$ believe that intelligent technologies will drive job growth in their companies in the next few years (Accenture, 2018, see also Ayoko \& Ashkanasy, 2020).

The adoption of DT, robotics and AI by contemporary organizations will continue to be on the rise. Researchers (e.g., Davenport, 2018) suggest that AI is now proclaimed as a means for business organizations to reduce costs and enhance the quality of services, coordination, and productivity, while practicing efficiencies and decision making (see Iansiti \& Lakhani, 2020; Kittur et al., 2019). Similarly, Boden (2016) argues that that these technologies are increasingly used in diverse organizational practices and in contemporary organizing.

Furthermore, these technologies assist in promoting innovation and JMO is involved in this conversation around the intersection between, DT, AI and robotics (see Brougham and Harr, 2018). We are aware that firms generally yearn for innovation to gain competitive advantage (Utterback, 1994). We are also aware that how firms manage their knowledge and resources are pivotal to their innovative behaviours (Mousa, Chowdhury, \& Gallagher, 2020; see also, Ayoko, 2021; Panda and Rath, 2021; Oh \& Kim, 2021). The above indicates the critical need for digital transformation, robotics, and AI in contemporary organisations.

Finally, and in organizational behavior, these emerging technologies have implications for cyber security issues (e.g., hacking, employee surveillances, HR practices, leadership, safety, working from home, hybrid work, collaboration, and employee wellbeing). The proliferation of these technologies also suggests that organizations must secure their technological platforms seriously and develop a more proactive and adaptive approach to the use of these technologies. JMO welcomes articles that help to tease out the implications of DT, robotics and AI on issues related to managing organizational behaviors.

\section{References}

Accenture (2018) Future workforce worker and C-Suite surveys: AI future workforce survey for insurance. Available at: https:// www.accenture.com/_acnmedia/accenture/conversion-assets/dotcom/documents/global/pdf/about-accenture/accenture-ai-futureworkforce-insurance-transcript.pdf (accessed 8, November 2021).

Appio, F. P., Frattini, F., Petruzzelli, A. M., \& Neirotti, P. (2021). Digital transformation and innovation management: A synthesis of existing research and an agenda for future studies.

Ayoko, O. B. (2021). SMEs, innovation, and human resource management. Journal of Management \& Organization, 27(1), $1-5$.

Ayoko, O. B., \& Ashkanasy, N. M. (2020). The physical environment of office work: Future open plan offices. Australian Journal of Management, 45(3), 488-506.

Balajee, N. (2020) What is Artificial Intelligence? https://nanduribalajee.medium.com/what-is-artificial-intelligencec68579db123 Accessed on the 8th of November 2021.

Boden, M. (2016). AI: Its nature and future. Oxford, UK: Oxford University Press 
Brougham, D., \& Haar, J. (2018). Smart technology, artificial intelligence, robotics, and algorithms (STARA): Employees' perceptions of our future workplace. Journal of Management \& Organization, 24(2), 239-257.

Davenport, T. H. (2018). The AI advantage: How to put the artificial intelligence revolution

Foerster-Metz, U. S., Marquardt, K., Golowko, N., Kompalla, A., \& Hell, C. (2018). Digital transformation and its implications on organizational behavior. Journal of EU Research in Business, 2018(S 3).

Hanelt, A., Bohnsack, R., Marz, D., \& Antunes Marante, C. (2021). A systematic review of the literature on digital transformation: insights and implications for strategy and organizational change. Journal of Management Studies, 58(5), 1159-1197.

Iansiti, M., \& Lakhani, K. R. (2020). From Disruption to Collision: The New Competitive Dynamics. MIT Sloan Management Review, 61(3), 34-39.

Kittur, A., Yu, L., Hope, T., Chan, J., Lifshitz-Assaf, H., Gilon, K., ... Shahaf, D. (2019). Scaling up analogical innovation with crowds and AI. Proceedings of the National Academy of Sciences, 116(6), 1870-1877.

Kretschmer, T., \& Khashabi, P. (2020). Digital transformation and organization design: An integrated approach. California Management Review, 62(4), 86-104.

Magistretti, S., Pham, C. T. A., \& Dell'Era, C. (2021). Enlightening the dynamic capabilities of design thinking in fostering digital transformation. Industrial Marketing Management, 97, 59-70.

McKinsey, (2017): Smartening up with artificial intelligence. https://www.mckinsey.com/industries/semiconductors/ourinsights/smartening-up-with-artificial-intelligence. Accessed on the $8^{\text {th }}$ of November, 202.

Mousa, F.-T., Chowdhury, J., \& Gallagher, S. R. (2020). The implications of CEO power on the relationship between firm resources and innovation. Journal of Management \& Organization, 2020, page 1-16.

Oh, S. Y., \& Kim, S. (2021). Effects of inter-and intra-organizational learning activities on SME innovation: the moderating role of environmental dynamism. Journal of Knowledge Management.

Panda, S., \& Rath, S. K. (2018). Information technology capability, knowledge management capability, and organizational agility: The role of environmental factors. Journal of Management \& Organization, 1-27.

Reier Forradellas, R. F., \& Garay Gallastegui, L. M. (2021). Digital Transformation and Artificial Intelligence Applied to Business: Legal Regulations, Economic Impact and Perspective. Laws, 10(3), 70.

Ruiz-Real, J. L., Uribe-Toril, J., Torres, J. A., \& De Pablo, J. (2021). Artificial intelligence in business and economics research: trends and future. Journal of Business Economics and Management, 22(1), 98-117.

Tang, D. (2021) What is digital transformation? EDPACS, 64:1, 9-13, DOI: 10.1080/07366981.2020.1847813

Ulrike Stefanie Foerster-Metz, Katrin Marquardt, Nina Golowko, Andreas Kompalla and Christian Hell (2018), Journal of EU Research in Business, DOI: 10.5171/2018.340873

Foerster-Metz, U. S., Marquardt, K., Golowko, N., Kompalla, A., \& Hell, C. (2018). Digital transformation and its implications on organizational behavior. Journal of EU Research in Business, 2018(S 3).

Utterback, J. (1994). Mastering the dynamics of innovation: How companies can seize opportunities in the face of technological change. University of Illinois at Urbana-Champaign's Academy for Entrepreneurial Leadership Historical Research Reference in Entrepreneurship.

$\mathrm{Xu}$, N., \& Wang, K. J. (2019). Adopting robot lawyer? The extending artificial intelligence robot lawyer technology acceptance model for legal industry by an exploratory study. Journal of Management \& Organization, 1-19.

Winkle K, Caleb-Solly P, Turton A, et al. (2019) Mutual shaping in the design of socially assistive robots: A case study on social robots for therapy. International Journal of Social Robotics. Epub ahead of print 7 March. DOI: 10.1007/ s12369-019-00536-9.

Zangiacomi, A., Pessot, E., Fornasiero, R., Bertetti, M., \& Sacco, M. (2020). Moving towards digitalization: a multiple case study in manufacturing. Production Planning \& Control, 31(2-3), 143-157.

Cite this article: Ayoko OB (2021). Digital Transformation, Robotics, Artificial Intelligence, and Innovation. Journal of Management \& Organization 27, 831-835. https://doi.org/10.1017/jmo.2021.64 